\title{
ABSTRAK \\ PENGARUH KONSENTRASI ZA TERHADAP KUALITAS NATA DE BANANA BERBAHAN DASAR KULIT PISANG KEPO
}

\author{
Farida Bahalwan, Dosen Prodi Pendidikan Biologi UNIDAR, Ambon \\ 081344872000, email: idha_banda07@yahoo.com
}

Hasil penelitian analisis inferensial baik indikator berat dan ketebalan diperoleh nilai dan hasil pengukuran yang tertinggi adalah pada konsentrasi ZA 9 gr/1000 ml $\left(\mathrm{X}_{2}\right)$ dengan nilai rata-rata tertinggi pada berat yaitu 51,6 gr dan untuk ketebalan nilai rata-rata tertinggi yaitu $1,37 \mathrm{~cm}$. Ini menunjukan bahwa kualitas nata de banana yang paling baik adalah menggunakan konsentrasi ZA $9 \mathrm{gr} / 1000 \mathrm{ml}\left(\mathrm{X}_{2}\right)$. Data hasil penelitian dihitung dengan menggunakan uji-F diperoleh nilai $\mathrm{F}$ hitung $=0,46$ baik untuk berat maupun ketebalannya, dan $\mathrm{F}$ tabel $5 \%=5,14$ dan $1 \%=10,92$, sehingga $\mathrm{H}_{0}$ diterima karena perlakuan memberikan pengaruh tidak signifikan terhadap variabel respon.

\section{Kata kunci : nata de banana, za}

\section{INFLUENCE OF CONCENTRATION OF ZA TO QUALITY NATA DE BANANA MADE FROM BANANA PEELS}

Inferensial analysis of research results both indicators of weight and thickness of the retrieved values and measuring results, the highest concentration was in the ZA $9 \mathrm{gr} / 1000 \mathrm{ml}\left(\mathrm{X}_{2}\right)$ with the highest average score on the weight is 51.6 gr and to the thickness of the highest average value is $1,37 \mathrm{~cm}$. This shows that the quality of nata de banana that is best to use concentration ZA 9 $\mathrm{gr} / 1000 \mathrm{ml}$ (X 2). Data research results calculated using the test-F retrieved value $\mathrm{F}=0.46$ count for both weight as well as its thickness, and $\mathrm{F}$ table $5 \%=$ 5.14 and $1 \%=10,92$, so $\mathrm{H}_{0}$ accepted because the treatment did not significantly influence the response variable.

Keywords: nata de banana, za

Pisang merupakan tanaman asli pegunungan yang agak tinggi. Bagi rakyat daerah tropis dan dapat ditemukan Indonesia pisang merupakan salah satu diseluruh wilayah Indonesia, mulai dari komuditas terpenting sesudah padi, daerah dataran rendah hingga daerah jagung, kelapa, dan kedelai serta 
merupakan sumber pendapatan yang dapat diandalkan. Pisang adalah tanaman serba guna karena seluruh bagian tanaman ini bermanfaat bagi kehidupan manusia sehingga tanaman ini sejak ratusan tahun dikenal di seluruh kepulauan Nusantara. Pisang memiliki peranan yang sangat penting dan peluang pengembangannya cukup besar karena dapat diolah menjadi berbagai produk.

Pemanfaatan limhah kulit pisang belum banyak diketahui orang, di Filipina dapat dibuat menjadi kompos atau briket.

Di Indonesia sendiri belum dimanfaatkan secara maksimal dan umumnya dibuang sebagai limbah domestik yang jika tersimpan dalam jangka waktu yang lama akan menimbulkan bau yang tidak sedap. Salah satu produk yang berasal dari limbah kulit pisang adalah nata de bananayang proses pembuatannya melibatkan mikroorganisme aerob berupa Acetobacter cylinum melalui teknik fermentasi. Nata de banana sama dengan nata de coco, yang berbeda adalah bahan bakunya, tetapi makanan kaya serat ini biasa dijadikan sebagai hidangan penutup berbentuk seperti jeli, berwarna putih hingga bening dan bertekstur kenyal.
Di daerah Maluku, limbah kulit pisangbelum banyak di pergunakan atau diolah menjadi suatu produk, biasanya hanya dibuang begitu saja, baik di daerah pedesaan maupun di daerah perkotaan, salah satu contoh di Kota Ambon yaitu di di daerah Silale, yang biasanya banyak terlihat tumpukan kulit pisang yang merupakan limbah dari penjual gorengan ataupun limbah yang berasal dari rumah tangga dan biasanya dalam jumlah yang banyak serta menimbulkan pencemaran lingkungan.

Mengingat potensi limbah kulit pisang yang demikian besar jumlahnya, yang setiap tahun cenderung mengalami peningkatan, maka pembuatan nata de banana yang menggunakan teknik fermentasi dapat diusahakan sebagai industri rumah tangga. Selama ini masyarakat menggunakan bahan-bahan yang agak sulit diperoleh dan harganya mahal, misalnya ammonium sulfat atau bahan kimia lainnya yang biasanya sangat sulit diperoleh, olehnya itu perlu adanya penelitian terkait dengan pembuatan nata de banana yang menggunakan bahan kimia murah, aman, dan mudah untuk diperoleh. Bahan kimia yang dimaksud seperti Amonium Sulfat yang bisa 
digantikan dengan menggunakan pupuk pendekatan eksperimen laboratorium ZA. menggunakan Rancangan Acak Lengkap

\section{METODE PENELITIAN}

\section{Jenis Penelitian}

(RAL) dengan 3 perlakuan dan 3 kali ulangan.

Jenis yang digunakan dalam

penelitian ini adalah korelasi dengan

Tabel 1. Desain Pengaruh Konsentrasi ZA Terhadap Berat dan Ketebalan Nata de banana.

\begin{tabular}{|c|c|c|c|c|c|}
\hline \multirow{2}{*}{ Kons ZA } & \multicolumn{3}{|c|}{ Ulangan } & \multirow{2}{*}{ Jumlah } & \multirow{2}{*}{ Rerata } \\
\cline { 2 - 5 } & $\mathbf{1}$ & $\mathbf{2}$ & $\mathbf{3}$ & & \\
\hline Konsentrasi $3 \mathrm{gr} / 1000 \mathrm{ml}\left(\mathrm{X}_{1}\right)$ & $\mathrm{X}_{1} \mathrm{Y}_{1}$ & $\mathrm{X}_{1} \mathrm{Y}_{2}$ & $\mathrm{X}_{1} \mathrm{Y}_{3}$ & $\mathrm{~T} \mathrm{X}_{1}$ & \\
\hline Konsentrasi $9 \mathrm{gr} / 1000 \mathrm{ml}\left(\mathrm{X}_{2}\right)$ & $\mathrm{X}_{2} \mathrm{Y}_{1}$ & $\mathrm{X}_{2} \mathrm{Y}_{2}$ & $\mathrm{X}_{2} \mathrm{Y}_{3}$ & $\mathrm{~T} \mathrm{X}_{2}$ & \\
\hline Konsentrasi $15 \mathrm{gr} / 1000 \mathrm{ml}\left(\mathrm{X}_{3}\right)$ & $\mathrm{X}_{3} \mathrm{Y}_{1}$ & $\mathrm{X}_{3} \mathrm{Y}_{2}$ & $\mathrm{X}_{3} \mathrm{Y}_{3}$ & $\mathrm{~T} \mathrm{X}_{3}$ & \\
\hline
\end{tabular}

Keterangan:

$\mathrm{X}=$ Konsentrasi ZA

$\mathrm{Y}=$ Berat dan Ketebalan nata de banana

\section{Variabel Penelitian}

Variabel dalam penelitian ini adalah :

a) Variabel bebas (X) adalah konsentrasi

$\mathrm{ZA}$, terdiri dari $\mathrm{X}_{1}$ (Konsentrasi 3 $\mathrm{gr} / 1000 \mathrm{ml}), \quad \mathrm{X}_{2} \quad$ (Konsentrasi 9 $\mathrm{gr} / 1000 \mathrm{ml}), \quad \mathrm{X}_{3} \quad$ (Konsentrasi 15 $\mathrm{gr} / 1000 \mathrm{ml})$

b) Variable terikat (Y) adalah kualitas nata de banana, yaitu rendemen (berat) dan ketebalan.

\section{Obyek Penelitian}

Obyek dalam penelitian ini adalah pengaruh konsentrasi ZA terhadap kualitas nata de banana. Dalam penelitian ini digunakan 3 perlakuan dan 3 kali ulangan sebagai total unit pengamatan 9 unit. 1 kali ulangan menggunakan kulit pisang sebanyak $1000 \mathrm{ml}$, jadi total kulit pisang yang digunakan adalah $3000 \mathrm{ml}$.

\section{Prosedur Penelitian}

a. Pembuatan medium fermentasi dan penambahan konsentrasi ZA.

Ke dalam $1000 \mathrm{ml}$ air perasan kulit pisang dilarutkan 10 gr gula pasir, dan ZA sesuai dengan konsentrasi yang diinginkan. Tambahkan asam asetat glasial 1,25 $\mathrm{ml}$ dan dibiarkan mendidih selama 10 menit. Biarkan medium dingin dalam keadaan panci tertutup. Setelah dingin medium dituang pada botol kultur dan diberi inokulum Acetobacter xylinum sebanyak $2 \mathrm{ml}$, tutup botol kultur dengan aluminium foil dan biarkan selama 2 minggu. Untuk konsentrasi ZA yang 
lainnya, prosedurnya sama, hanya jumlah ZA yang digunakan berbeda.

b. Pengukuran Hasil Fermentasi

Setelah waktu fermentasi berlangsung selama 14 hari, maka nata de banana siap dipanen. Untuk pengukuran berat nata de banana dilakukan dengan timbangan Ohaus 8724 dengan kapasitas 311 gr. Disamping itu diadakan pool pendapat dari 10 responden mengenai warna (tingkat keputihan), dan tingkat kekenyalan. Jumlah responden sebanyak 10 orang dengan kriteria adalah orang yang sering mengkonsumsi nata de banana. Untuk pengukuran ketebalan nata de banana digunakan mistar.

\section{Teknik Analisis Data}

a. Analisis Deskriptif, dilakukan untuk membahas kualitas (uji organoleptik) dari Warna, dan kekenyalannata de banana dengan menggunakan angket

b. Analisis inferensial dilakukan untuk menguji hipotesis terkait rendemen dan ketebalan

\section{HASIL PENELITIAN}

\section{Warna (tingkat keputihan) Nata de banana}

Dari hasil uji organoleptik terhadap warna (tingkat keputihan) nata de banana dari tiga konsentrasi ZA yang berbeda yakni 3 gr/1000 ml, 9 gr/1000 ml dan $15 \mathrm{gr} / 1000 \mathrm{ml}$, sesuai dengan pendapat dari 10 orang responden yang diambil dari mahasiswa yang sering mengkonsumsi nata de banana yaitu 6 orang responden menilai warnanya putih, 2 orang responden menilainya cukup putih dan 2 orang responden menilai warnanya kurang putih.

\section{Kekenyalan Nata de banana}

Dari hasil uji organoleptik terhadap tingkat kekenyalan nata de banana dari tiga konsentrasi ZA yang berbeda sesuai dengan pendapat dari 10 orang responden yang di ambil dari mahasiswa yang sama dalam menilai warna (tingkat keputihan) nata de banana yakni 9 orang responden menilainya cukup kenyal dan 1 orang responden menilainya kurang kenyal.

\section{Berat Nata de banana}

Dari hasil pengukuran berat nata de banana dari tiga konsentrasi ZA yakni konsentrasi $3 \mathrm{gr} / 1000 \mathrm{ml}\left(\mathrm{X}_{1}\right), 9 \mathrm{gr} / 1000$ 
$\mathrm{ml}\left(\mathrm{X}_{2}\right)$ dan $15 \mathrm{gr} / 1000 \mathrm{ml}\left(\mathrm{X}_{3}\right)$ disajikan dalam tabel di bawah ini:

Tabel 2. Rata-rata berat Nata de banana yang dihasilkan dari ketiga konsentrasi

\begin{tabular}{|c|l|c|}
\hline No & \multicolumn{1}{|c|}{ Perlakuan } & Rata-rata Berat Nata de banana \\
\hline 1. & Konsentrasi $3 \mathrm{gr} / 1000 \mathrm{ml}$ & $48,7 \mathrm{gr}$ \\
\hline 2. & Konsentrasi $9 \mathrm{gr} / 1000 \mathrm{ml}$ & $51,6 \mathrm{gr}$ \\
\hline 3. & Konsentrasi $15 \mathrm{gr} / 1000 \mathrm{ml}$ & $37,7 \mathrm{gr}$ \\
\hline
\end{tabular}

Berdasarkan hasil pengukuran rata- Sedangkan analisis sumber ragam rata berat nata de banana pada tabel di terhadap rata-rata berat nata de banana atas, terlihat bahwa hasil pengukuran berat pada ketiga konsentrasi ZA tersebut dapat nata de banana yang tertinggi diperoleh di lihat pada tabel di bawah ini dan pada perlakuan konsentrasi $9 \mathrm{gr} / 1000 \mathrm{ml}$ perhitungan disajikan dalam Analisis Uji$\left(\mathrm{X}_{2}\right)$, dengan nilai rata-rata 51,6 gr. $\mathrm{F}$.

Tabel 3.Analisis Varians Berat Nata de banana

\begin{tabular}{|c|c|c|c|c|c|c|}
\hline \multirow{2}{*}{ Sumber ragam } & \multirow{2}{*}{ DB } & \multirow{2}{*}{ JK } & \multirow{2}{*}{ KT } & \multirow{2}{*}{ F $_{\text {hitung }}$} & \multicolumn{2}{|c|}{$F_{\text {tabel }}$} \\
\hline & & & & & $5 \%$ & $1 \%$ \\
\hline Perlakuan & 2 & 320,17 & 160,08 & \multirow{3}{*}{$0,46^{\mathrm{tn}}$} & \multirow{3}{*}{5,14} & \multirow{3}{*}{10,92} \\
\hline Galat & 6 & 2082,6689 & 347,11 & & & \\
\hline Total & 8 & 2402,8389 & 300,35 & & & \\
\hline
\end{tabular}

Keterangan $:$ tn $=$ tidak signifikan

Setelah dilakukan perhitungan Uji-

$\mathrm{F}$ untuk berat nata de banana dari ketiga perlakuan konsentrasi ZA yang berbeda, diperoleh nilai $\mathrm{F}_{\text {hitung }}(0,46)<\mathrm{F}$ tabel, oleh karena itu, $\mathrm{H}_{0}$ diterima yang berarti tidak ada perbedaan pengaruh konsentrasi ZA terhadap berat nata de banana yang dihasilkan.

\section{Ketebalan Nata de banana}

Dari hasi pengukuran ketebalan nata de banana dari ketiga konsentrasi ZA yakni konsentrasi $3 \mathrm{gr} / 1000 \mathrm{ml}\left(\mathrm{X}_{1}\right), 9$ $\mathrm{gr} / 1000 \mathrm{ml}\left(\mathrm{X}_{2}\right)$ dan $15 \mathrm{gr} / 1000 \mathrm{ml}\left(\mathrm{X}_{3}\right)$, sedangkan nilai rata-rata hasil pengukuran terhadap ketebalan dari ketiga konsentrasi tersebut disajikan dalam tabel di bawah ini:

Tabel 4.Rata-rata ketebalan nata de banana yang dihasilkandari ketiga konsentrasi

\begin{tabular}{|c|l|c|}
\hline No & \multicolumn{1}{|c|}{ Perlakuan } & Rata-rata ketebalan nata de banana \\
\hline 1. & Konsentrasi $3 \mathrm{gr} / 1000 \mathrm{ml}$ & $1,30 \mathrm{~cm}$ \\
\hline 2. & Konsentrasi $9 \mathrm{gr} / 1000 \mathrm{ml}$ & $1,37 \mathrm{~cm}$ \\
\hline 3. & Konsentrasi $15 \mathrm{gr} / 1000 \mathrm{ml}$ & $0,97 \mathrm{~cm}$ \\
\hline
\end{tabular}

Berdasarkan dari hasi pengukuran banana pada tabel di atas, terlihat bahwa terhadap nilai rata-rata ketebalan nata de hasil pengukuran ketebalan nata de 
banana yang tertinggi diperoleh pada rata ketebalan nata de banana pada ketiga perlakuan konsentrasi $9 \mathrm{gr} / 1000 \mathrm{ml}\left(\mathrm{X}_{2}\right)$ konsentrasi ZA tersebut dapat dilihat pada dengan nilai rata-rata $1,37 \mathrm{~cm}$. Sedangkan tabel di bawah ini, dan perhitungan analisis sumber ragam terhadap nilai rata- disajikan dalam analisis Uji-F.

Tabel 5. Analisis Varians Ketebalan Nata de banana

\begin{tabular}{|c|c|c|c|c|c|c|}
\hline \multirow{2}{*}{ Sumber ragam } & \multirow{2}{*}{ DB } & \multirow{2}{*}{ JK } & \multirow{2}{*}{ KT } & \multirow{2}{*}{$\mathbf{F}$ hitung } & \multicolumn{2}{|c|}{$F_{\text {tabel }}$} \\
\hline & & & & & $5 \%$ & $1 \%$ \\
\hline Perlakuan & 2 & 0,27 & 0,13 & \multirow{3}{*}{$0,46^{\mathrm{tn}}$} & \multirow{3}{*}{5,14} & \multirow{3}{*}{10,92} \\
\hline Galat & 6 & 1,6645 & 0,28 & & & \\
\hline Total & 8 & 1,9345 & 0,24 & & & \\
\hline
\end{tabular}

Keterangan $:$ tn $=$ tidak signifikan

Setelah dilakukan perhitungan Uji-F untuk ketebalan nata de banana dari ketiga perlakuan konsentrasi ZA yang berbeda, diperoleh nilai $\mathrm{F}$ hitung $(0,46)<\mathrm{F}$ tabel, oleh karena itu, $\mathrm{H}_{0}$ diterima yang berarti tidak ada perbedaan pengaruh konsentrasi ZA terhadap ketebalan nata de banana yang dihasilkan.

\section{PEMBAHASAN}

Pupuk ZA mengandung Nitrogen (20-21\%), sulfur (23-24\%). Karena banyaknya kandungan sulfurnya maka pupuk ZA sangat berguna bagi pertumbuhan tanaman yang banyak membutuhkan unsur belerang. Dalam pembuatan nata de banana memerlukan bantuan mikroorganisme, dalam hal ini adalah bakteri aerob yaitu Acetobacter xylinum dan bakteri tersebut mempunyai berbagai kriteria kehidupan seperti kadar keasaman $(\mathrm{pH})$ 3-4 dan ketersediaan nitrogen yang cukup, sehingga ZA yang ada merupakan sumber nitogen bagi kelangsungan proses metabolisme yang terjadi dan nitrogen tersebut akan di cerna/terdegradasi oleh bakteri dan tidak terkandung dalam nata karena habis di konsumsi bakteri dengan catatan kadarnya sesuai.

Hasil analisis deskriptif kualitatif pada uji organoleptik mengenai warna dan kekenyalan nata de banana dari ketiga konsentrasi yang berbeda yakni 3 gr/1000 $\mathrm{ml}\left(\mathrm{X}_{1}\right), 9 \mathrm{gr} / 1000 \mathrm{ml}\left(\mathrm{X}_{2}\right)$ dan $15 \mathrm{gr} / 1000$ $\mathrm{ml} \quad\left(\mathrm{X}_{3}\right), \quad$ memperlihatkan adanya perbedaan yang dibuktikan dari pendapat 10 orang responden, yang hasilnya menunjukan tidak semua dari ketiga konsentrasi ZA tersebut sama, dalam hal ini ada yang menilai warnanya (tingkat keputihan) putih, cukup putih, dan kurang 
putih serta untuk tingkat kekenyalan ada yang menilainya cukup kenyal dan kurang kenyal. Untuk hasil analisis deskriptif kuantitatif pada berat dan ketebalan nata de banana, dimana nilai rata-rata pada konsentrasi $3 \mathrm{gr} / 1000 \mathrm{ml}\left(\mathrm{X}_{1}\right)$ untuk berat 48,7 gr, ketebalannya $1,30 \mathrm{~cm}$, konsentrasi $9 \mathrm{gr} / 1000 \mathrm{ml}\left(\mathrm{X}_{2}\right)$ untuk berat 51,6 gr, ketebalannya $1,37 \mathrm{~cm}$, dan konsentrasi $15 \mathrm{gr} / 1000 \mathrm{ml}\left(\mathrm{X}_{3}\right)$ untuk berat $37,7 \mathrm{gr}$, ketebalannya $0,97 \mathrm{~cm}$, ini menunjukan bahwa adanya perbedaan nilai rata-rata dari berat dan ketebalannya, dimana untuk berat dan ketebalan nata de banana yang lebih besar mengacu pada konsentrasi $9 \mathrm{gr} / 1000 \mathrm{ml}\left(\mathrm{X}_{2}\right)$.

Penelitian ini membuktikan bahwa dari ketiga konsentrasi ZA yang digunakan sebagai tambahan nutrisi yang digunakan oleh bakteri nata yaitu Acetobacter xylinum, ternyata konsentrasi ZA $9 \mathrm{gr} / 1000 \mathrm{ml}\left(\mathrm{X}_{2}\right)$ memberikan produk nata de banana yang terbaik, baik dari segi warna, kekenyalan maupun dari segi berat dan ketebalannya. Dalam penelitian yang dilakukan dari ketiga konsentrasi ZA ternyata memberikan hasil yang berbeda terutama pada konsentrasi ZA 15 gr/1000 $\mathrm{ml}\left(\mathrm{X}_{3}\right)$, dimana pada konsentrasi ini dari ketiga ulangan mengalami keterlambatan dalam pembentukan nata de banana, ini disebabkan karena kelebihan konsentrasi ZA yang digunakan, sehingga kemampuan bakteri Acetobacter xylinum untuk membentuk nata de banana berkurang, dan nata de banana yang dihasilkan juga kurang berkualitas, baik dari segi warna, kekenyalan serta berat dan ketebalannya.

Untuk berat dan ketebalan nata de banana yang diteliti tanpa uji organoleptik oleh responden melainkan melalui pengukuran langsung dengan menimbang hasil produk nata de banana yang dihasilkan. Bila produk nata de banana semakin berat dan tebal berarti jumlah serat karbohidrat yang tersusun dalam produk nata de banana semakin banyak, dan apabila hasil pengukuran produk nata de banana semakin ringan dan tipis berarti jumlah serat karbohidrat yang tersusun dalam produk nata de banana semakin kecil. Pernyataan diatas sesuai dengan penelitian dari ketiga konsentrasi ZA, karena pada konsentrasi ZA 9 gr/1000 ml $\left(\mathrm{X}_{2}\right)$ lebih berat dan tebal dari konsentrasi ZA 3 gr/1000 $\mathrm{ml}\left(\mathrm{X}_{1}\right)$ dan konsentrasi ZA $15 \mathrm{gr} / 1000 \mathrm{ml}\left(\mathrm{X}_{3}\right)$. Berarti konsentrasi ZA 9 gr/1000 $\mathrm{ml} \quad\left(\mathrm{X}_{2}\right)$ memproduksi karbohidrat untuk kebutuhan bakteri nata 
lebih besar sehingga nata de banana yang dihasilkan lebih berat dan tebal pula.

\section{KESIMPULAN}

1. Ada perbedaan pengaruh konsentrasi ZA terhadap warna dan kekenyalan produk nata de banana, tetapi tidak ada perbedaan pengaruh konsentrasi terhadap berat dan ketebalan produk nata de banana.

2. Konsentrasi ZA yang terbaik dalam penelitian ini adalah $9 \mathrm{gr} / 1000 \mathrm{ml}$.

\section{SARAN}

1. Disarankan kepada pembuat nata de banana untuk memberikan ZA pada konsentrasi 9 gr/1000 $\mathrm{ml}$ dalam medium yang digunakan.

2. Pengaruh pemberian konsentrasi ZA yang lebih tinggi atau lebih rendah dalam proses fermentasi kulit pisang terhadap kualitas nata de banana tidak akan menghasilkan produk nata de banana yang berkualitas, sehingga diperlukan konsentrasi yang optimum untuk pertumbuhan nata de banana yang baik dan optimal.

3. Perlunya diperhatikan alat, bahan, dan ruangan tempat fermentasi nata de banana yang benar-benar steril (bebas dari kontaminan).

\section{DAFTAR PUSTAKA}

Anonim. 1998. Dasar-Dasar Bercocok Tanam. Kanisius. Yokyakarta

Indranada H.K. 1989. Pengelolaan Kesuburan Tanah. Bina Aksara. Jakarta

Hanafiah A.K. 1993. Rancangan Percobaan. Raja Grafindo. Jakarta

Indranada H.K. 1989. Pengelolaan Kesuburan Tanah. Bina Aksara. Jakarta

La Teng N.P. 1990.Pengaruh Pupuk dan Jumlah Sel Mikroba Starter pada Pembuatan Nata de banana. Unhas. Ujung Pandang

Noverta EBT. 1996. Budidaya kelapa Kopyor. Mataram Agung. Jakarta

Palunkun R. 1993. Aneka Produk Olahan Kelapa. Penebar Swadaya. Jakarta

Pambayun R. 2002. Teknologi Pengolahan Nata de banana. Kanisius. Yokyakarta

Setyamidjaja D. 1991. Bertanam Kelapa. Kanisius. Yokyakarta

Sofyan A. 1994. Studi Beberapa Pupuk Nitrogen dengan Rhizobium Terhadap Hasil Panen KacangKacangan. Balai Pengkajian Teknologi Pertanian. Malang

Suhardiyono. 1993. Tanaman Kelapa dan Pemanfaatannya. Kanisius. Yokyakarta

Sumartono. 1982. Kelapa. Bumi Restu. Jakarta

Sutrisno T. 1989. Pemupukan dan Pengolahan Tanah. Armico. Bandung

Warisno. 1998. Budidaya Kelapa Kopyor. Kanisius. Yokyakarta 